Contract No. and Disclaimer:

This manuscript has been authored by Savannah River Nuclear Solutions, LLC under Contract No. DE-AC09-08SR22470 with the U.S. Department of Energy. The United States Government retains and the publisher, by accepting this article for publication, acknowledges that the United States Government retains a non-exclusive, paid-up, irrevocable, worldwide license to publish or reproduce the published form of this work, or allow others to do so, for United States Government purposes. 
SRNL-STI-2012-00575

\section{Modeling Ion-Exchange Processing with Spherical Resins for Cesium Removal}

by

T. Hang, C. A. Nash, and S. E. Aleman

Savannah River National Laboratory

Aiken, SC 29808

A paper proposed for publication in

Separation Science and Technology

Publisher: Taylor \& Francis

41 Mortimer Street

London, W1T 3JH, UK

This paper was prepared in connection with work done under Contract No. DE-AC09-08SR22470 with the U. S. Department of Energy. By acceptance of this paper, the publisher and/or recipient acknowledges the U. S. Government's right to retain a nonexclusive, royalty-free license in and to any copyright covering this paper, along with the right to reproduce and to authorize others to reproduce all or part of the copyrighted paper. 


\title{
Modeling Ion-Exchange Processing with Spherical Resins for Cesium Removal
}

\author{
T. Hang ${ }^{1}$, C. A. Nash, and S. E. Aleman
}

Savannah River National Laboratory, Aiken, SC

\begin{abstract}
The spherical Resorcinol-Formaldehyde and hypothetical spherical SuperLig ${ }^{\circledR} 644$ ion-exchange resins are evaluated for cesium removal from radioactive waste solutions. Modeling results show that spherical SuperLig® 644 reduces column cycling by $50 \%$ for highpotassium solutions. Spherical Resorcinol Formaldehyde performs equally well for the lowestpotassium wastes. Less cycling reduces nitric acid usage during resin elution and sodium addition during resin regeneration, therefore, significantly decreasing life-cycle operational costs. A model assessment of the mechanism behind "cesium bleed" is also conducted. When a resin bed is eluted, a relatively small amount of cesium remains within resin particles. Cesium can bleed into otherwise decontaminated product in the next loading cycle. The bleed mechanism is shown to be fully isotherm-controlled vs. mass transfer controlled. Knowledge of residual postelution cesium level and resin isotherm can be utilized to predict rate of cesium bleed in a mostly non-loaded column. Overall, this work demonstrates the versatility of the ion-exchange modeling to study the effects of resin characteristics on processing cycles, rates, and cold chemical consumption. This evaluation justifies further development of a spherical form of the SL644 resin.
\end{abstract}

Keywords: Ion-exchange; cesium removal; spherical resins; process modeling; radioactive waste

\footnotetext{
${ }^{1}$ Address correspondence to T. Hang: Savannah River National Laboratory, Aiken, SC 29808, USA.

E-mail: thong.hang@srnl.doe.gov
} 
SRNL-STI-2012-00575

\section{INTRODUCTION}

To support tank closures at the Savannah River Site (SRS) in South Carolina and the Hanford Site in Washington State, radioactive liquid wastes contained in the storage tanks must be

processed. ${ }^{137} \mathrm{Cs}$ is a major contribution to the radioactivity of these waste solutions. Ionexchange is a mature technology for treating radioactive liquid waste $(1,2)$. Several ionexchange resins such as crystalline silico-titanate (CST) (3) and resorcinol-formaldehyde (RF) $(4,5)$ have shown high selectivity to remove cesium from radioactive wastes. A new separation technology called Small Column Ion Exchange (SCIX) is being considered that would allow insitu treatment of stored wastes. "Small Column" means small relative to industrial sized columns, so that it can completely fit down a waste storage tank riser. Figure 1 illustrates the concept of a 2-column SCIX process in a waste tank. The SCIX concept consists of Rotary Microfilters (RMF), Submersible Mixing Pumps (SMP), and ion-exchange columns. The RMFs provide filtration to remove insoluble solids in the feed stream after actinide removal. The ionexchange units remove cesium from the salt solution in the tank. Each column may be 20 feet tall and 2 feet in diameter and is designed to fit down a tank riser. In-tank mounting of equipment requires minimal additional shielding. At SRS, the decontaminated salt waste would be processed in the Saltstone facility and disposed, while the cesium, actinides and solid components would be immobilized in the Defense Waste Processing Facility (DWPF). 


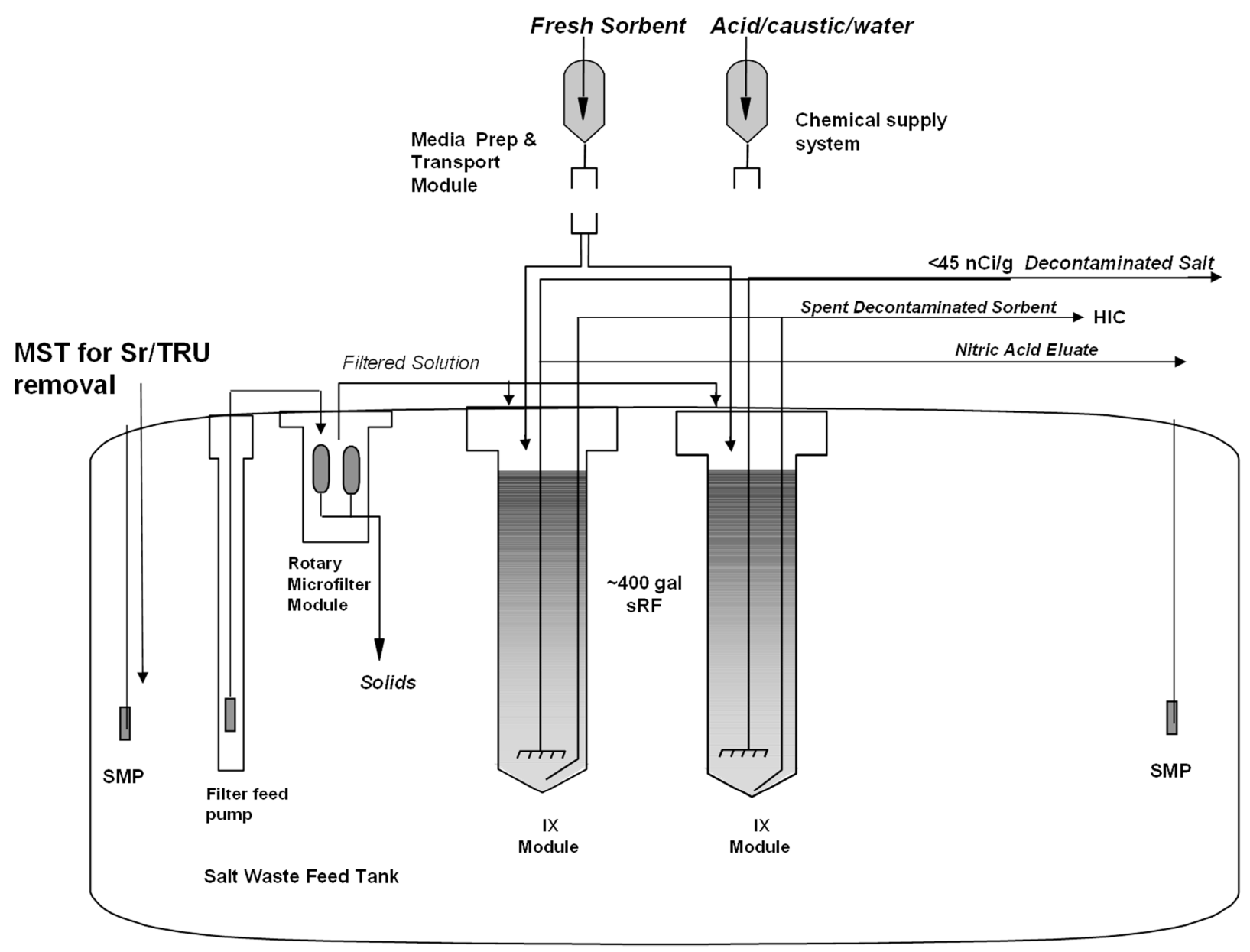

FIG. 1. Concept for an In-Tank SCIX process

The RF resin was patented by the Savannah River National Laboratory (SRNL) (6) to remove cesium from highly alkaline wastes. The resin is a resorcinol $\left(\mathrm{C}_{6} \mathrm{H}_{6} \mathrm{O}_{2}\right)$ formaldehyde $\left(\mathrm{CH}_{2} \mathrm{O}\right)$ condensation polymer. This resin has a strong preference for $\mathrm{H}^{+}$and can be eluted by using acid to remove $\mathrm{Cs}^{+}$and its competitors. RF relative affinities have been estimated to be $\mathrm{H}^{+}>\mathrm{Cs}^{+}>$ $\mathrm{Rb}^{+}>\mathrm{K}^{+}>\mathrm{Na}^{+}$. The RF resin can withstand multiple cycles of loading and acid elution before its usefulness is exhausted. The original ground-gel form of the RF resin contained shards and irregular shaped particles, causing significant flow resistance and inconsistent results as shards cracked and broke down, creating fines. Because of the poor hydraulic performance of the ground-gel form, the RF resin was improved by the Waste Treatment and Immobilization Plant 
DOE River Protection Project at the Hanford Site. RF was processed into microspheres by Microbeads AS, in Skedsmokorset, Norway, leading to much better and consistent flow performance (7-9). In its spherical form the RF resin is referred to as $\mathrm{SF}$.

IBC Advanced Technologies, Inc. (American Fork, UT) developed proprietary sequestering ligand agents (referred to as SuperLig ${ }^{\circledR}$ ) that selectively remove various radionuclides (cesium, strontium, etc.) from highly alkaline solutions based on molecular recognition technology and macrocyclic chemistry (covalent bonding). One of these materials (SuperLig ${ }^{\circledR} 644$ or SL644) can remove cesium from simulated and actual Hanford Site alkaline waste even in the presence of excess quantities of sodium and potassium (10). The chemical and radiolytic stability of SL644 material was investigated (11) and found to be sufficiently stable for cesium ionexchange removal processes in alkaline supernates. The relative affinities of SL644 resin for ion-exchange were estimated to be $\mathrm{H}^{+}>>\mathrm{Cs}^{+}>>\mathrm{K}^{+}>\mathrm{Na}^{+}$. In general, the SL644 shape is not spherical and can swell upon exposure to liquid solutions of varying alkalinity (i.e., can more than double its size from dry to aqueous conditions). Similar to the RF resin, the SL644 resin beds exhibit hydraulic problems in its nonspherical form. Hence, it would be of great interest to explore a potential development of a spherical form of the SL644 resin.

Modeling studies have been conducted for both SL644 and SRF resins on radioactive alkaline wastes stored at the Hanford Site and the SRS (12-14). One significant difference between those wastes is the concentration of potassium. In general, SRS wastes have low concentrations of potassium. Potassium is a major competitor of cesium for sites on the sRF resin so its presence will affect loading performance. In this study, a hypothetical (virtual) spherical SL644 is evaluated for removal of cesium from both Hanford and SRS waste solutions. The spherical SL644 performances were compared to those of sRF to assess the need for further development 
SRNL-STI-2012-00575

and testing. An assessment of the mechanism behind "cesium bleed" from the resin bed into otherwise decontaminated product in the loading cycle is also provided.

\section{ION-EXCHANGE MODELING}

Modeling ion-exchange columns for cesium removal from radioactive liquid wastes was presented in previous ion-exchange studies at SRNL (12-15). The following sections discuss the key methodologies used to model ion-exchange column behavior.

The competition for cation exchange loading at the resin sites is primarily among cesium, rubidium, potassium, and sodium for the cesium-sRF resin system or among cesium, potassium, and sodium for the cesium-SL644 resin system. Based on available batch equilibrium studies, the relative affinities for adsorption have been computed to be $\mathrm{Cs}+>\mathrm{Rb}+>\mathrm{K}+>\mathrm{Na}+$ for $\mathrm{RF}$ (13) and $\mathrm{Cs}+>>\mathrm{K}+>\mathrm{Na}+$ for SL644 (12). Given this information, early column performance (i.e., the first 5 to 10 bed volumes) generally requires the use of the multi-component formulations. Long-term performance however should be adequately handled using a simpler "effective" single-component formulation as discussed below.

In this model the kinetics associated with local ion-exchange at an active resin site are assumed to be very fast (faster than the various liquid mass transfer mechanisms that transport ions to that site). Assuming radial effects to be negligible within the active region of the packed bed (i.e., a large column-to-particle diameter ratio), a one-dimensional solute (ion) transport equation for the mobile phase within the bed becomes

$$
\begin{aligned}
& \frac{\partial C}{\partial t} \quad=\quad E_{b} \frac{\partial^{2} C}{\partial z^{2}} \quad-u_{o} \frac{\partial C}{\partial z} \quad-\frac{3\left(1-\varepsilon_{b}\right) k_{f}}{R_{p} \varepsilon_{b}}\left(C-C_{p, r=R_{p}}\right) \\
& \text { storage axial advection liquid film diffusion } \\
& \text { dispersion (mass transfer) }
\end{aligned}
$$


with boundary and initial conditions

$$
\begin{array}{ll}
\mathrm{z}=0: & E_{b} \frac{\partial C}{\partial z}=u_{o}\left(C(t, 0)-C_{o}\right) \\
\mathrm{z}=\mathrm{L}: & \frac{\partial C}{\partial z}=0 \\
\mathrm{t}=0: & C=C(0, z)
\end{array}
$$

Assuming uniformly sized spherical particles with a homogeneous distribution of pores, a onedimensional species transport equation for the pore phase within an average sized particle of resin becomes

$\varepsilon_{p} \frac{\partial C_{p}}{\partial t}+\left(1-\varepsilon_{p}\right)\left(\frac{\partial Q}{\partial C_{p}}\right) \frac{\partial C_{p}}{\partial t} \quad=\quad \varepsilon_{p} \frac{D_{p}}{r^{2}} \frac{\partial}{\partial r}\left(r^{2} \frac{\partial C_{p}}{\partial r}\right)$

storage $\quad$ surface adsorption $\quad$ Fickian pore diffusion

subjected to boundary and initial conditions

$$
\begin{array}{ll}
\mathrm{r}=0: & \frac{\partial C_{p}}{\partial r}=0 \\
\mathrm{r}=\mathrm{R}_{\mathrm{p}}: & \varepsilon_{p} D_{p} \frac{\partial C_{p}}{\partial r}=k_{f}\left(C-C_{p, r=R_{p}}\right) \\
\mathrm{t}=0: & C_{p}=C_{p}(0, r)
\end{array}
$$

\section{VERSE-LC Code}

The VERSE-LC (VErsatile Reaction Separation simulator for Liquid Chromatography) Version 7.8 code developed at Purdue University $(16,17)$ was chosen based on its availability and acceptance in this field. Prior to applying VERSE-LC to the ion-exchange modeling, the code was thoroughly verified by SRNL researchers (18). The verification process provided quality assurance that the installed PC version of VERSE-LC was capable of adequately solving the above mentioned governing equations and also helped researchers better understand how to 
accurately use the VERSE-LC code (e.g., mesh refinement requirements and input/output options). For all results presented in this paper, numerical errors associated with the results of VERSE-LC should be very small when compared to the uncertainties associated with various model input parameters (bed density, particle radius, pore diffusion etc.).

\section{Equilibrium Cesium Isotherms}

To perform column transport simulations, an "effective" single-component isotherm model in an algebraic form must be available to represent the $\mathrm{Q}-\mathrm{C}_{\mathrm{p}}$ relationship. A simple form of isotherm (i.e., Langmuir isotherm) is given as

$$
Q=\frac{\bar{C}_{T} C_{p}}{\beta+C_{p}}
$$

An empirical extension of this to the Freundlich/Langmuir form introduces powers on the concentration terms to obtain

$$
Q=\frac{\bar{C}_{T} C_{p}^{M_{a}}}{\beta+C_{p}^{M_{b}}}
$$

The VERSE-LC Freundlich/Langmuir Hybrid isotherm model was selected in which the surface loading for cesium on the resin material is expressed as

$$
\bar{C}_{p}=\frac{a C_{p}^{M_{a}}}{\beta+C_{p}^{M_{b}}}
$$

Eq. (5) is equivalent to Eq. (4) with the exception that $\bar{C}_{p}$ is expressed in terms of mol per liter of bed volume whereas Q is in mol per gram resin. The VERSE-LC parameter $a$ in Eq. (5) is therefore computed as

$$
a=\rho_{b} \eta_{d f} \bar{C}_{T}
$$

The $\beta$ parameter for cesium depends upon the other ionic competitors for adsorption (i.e., $\mathrm{K}+$, 
SRNL-STI-2012-00575

$\mathrm{Na}+$ ). The $\beta$ parameter contains the selectivity coefficients making it dependent upon temperature and liquid composition of all of the ionic species in solution. The larger the $\beta$ parameter the less favorable (lower loadings) an isotherm will be. The $a$ parameter as given in Eq. (6) includes the degradation factor $\left(\eta_{d f}\right)$. The degradation factor is unity when considering a fresh resin and becomes less than unity during chemical exposure (i.e., cycling).

For each particular feed stream at a given temperature, the parameters $a, \beta, M_{a}$ and $M_{b}$ are estimated by fitting the isotherm equation to simulated data generated by the thermodynamic equilibrium CERMOD (Cation Exchange Resin Model) and TMIXP (Thermodynamic Model for Ion Exchange Processes) codes for the sRF and SL644 resins, respectively. Both TMIXP (12) and CERMOD (19) codes were developed at SRNL.

\section{Axial Dispersion}

Axial dispersion in packed columns is the result of mechanical dispersion added onto molecular diffusion. For practical flowrates mechanical dispersion dominates. In the Reynolds number range of interest (i.e., 0.001 to 1000), the Chung and Wen correlation (20) is applicable for sufficiently large columns (i.e., large diameter and length) and is expressed as

$$
E_{b}=\frac{2 R_{p} u_{o} \varepsilon_{b}}{0.2+0.011 \mathrm{Re}^{0.48}}
$$

where the Reynolds number is defined as

$$
\mathrm{Re}=\frac{2 R_{p} u_{o} \varepsilon_{b} \rho}{\mu}
$$

The standard deviation of this correlation based on all available data points was reported to be 46\%. The Chung and Wen correlation applies for only sufficiently large columns and correction factors must be considered for columns with small diameters and/or short active bed lengths. The study cases in this work have the Reynolds numbers ranging from 0.2 to 1.1 . 
SRNL-STI-2012-00575

\section{Film Diffusion}

VERSE-LC has the Wilson and Geankoplis correlation as an option, and this correlation falls well within the spread of available low Reynolds number data (i.e., 0.0016 to 55). For each ion species $i$ considered, the Wilson and Geankoplis correlation (21) is expressed as

$$
J \equiv\left[\frac{k_{f, i}}{u_{o} \varepsilon_{b}}\right] S c_{i}^{2 / 3}=\frac{1.09}{\varepsilon_{b}} \mathrm{Re}^{-2 / 3}
$$

with

$$
S c_{i}=\frac{\mu}{\rho D_{\infty, i}}
$$

A standard deviation of approximately $25 \%$ is reported for this correlation by Wilson and Geankoplis.

\section{Pore Diffusion}

In the VERSE-LC code, the model for intraparticle diffusion assumes that the particles are spheres of uniform radius. To apply the VERSE-LC model it is therefore necessary to determine an average radius from the particle size distribution and an effective pore diffusivity.

Assuming that the pore sizes are large relative to the size of the migrating ions of interest, pore diffusion coefficients should not be significantly lower than their bulk or free stream values. However, some level of reduced diffusion in the pores is expected resulting from bends along the pore paths that are generally accounted for by a particle tortuosity factor $\tau$ defined as

$$
D_{p}=\frac{D_{\infty}}{\tau}
$$

The cesium diffusivity in the bulk feed solution, $D_{\infty}$, was calculated using the Nernst-Haskell equation. Tortuosity factors for SL644 and sRF resin have been determined $(12,13)$ by analyzing experimental data obtained. It was found that using $\tau=3$ gave reasonable results. 
SRNL-STI-2012-00575

\section{WASTE PROPERTIES}

In the column simulations performed in this study, feeds at varying compositions from the wastes stored at Hanford and the SRS were considered:

- Hanford: Hot Commissioning (HC), Envelope B (EB), and Subsequent Operations (SO). All feeds are at nominal compositions.

- SRS: Tank 3 and Tank 37.x

SRS waste is generally lower in potassium and organic components than Hanford waste. The feed major compositions are listed in Table 1. Other feed properties (i.e., diffusivity, density, and viscosity) are shown in Table 2. Feed data (compositions, properties) were obtained from Aleman et al (13) and Smith (14) for Hanford and SRS wastes, respectively.

TABLE 1. Feed compositions

\begin{tabular}{cccccc}
\hline $\begin{array}{c}\text { Species } \\
(\mathrm{M})\end{array}$ & $\begin{array}{c}\text { Hot } \\
\text { commissioning }\end{array}$ & Envelope B & $\begin{array}{c}\text { Subsequent } \\
\text { operations }\end{array}$ & $\begin{array}{c}\text { Tank 3 } \\
\text { (SRS) }\end{array}$ & $\begin{array}{c}\text { Tank 37 } \\
\text { (SRS) }\end{array}$ \\
\hline $\mathrm{K}^{+}$ & 0.48 & 0.091 & 0.15 & 0.002 & 0.01 \\
$\mathrm{Na}^{+}$ & 4.57 & 4.13 & 4.60 & 6.0 & 6.0 \\
$\mathrm{Cs}^{+}$ & $2.74 \times 10^{-5}$ & $2.83 \times 10^{-4}$ & $5.0 \times 10^{-5}$ & $6.35 \times 10^{-5}$ & $1.08 \times 10^{-4}$ \\
$\mathrm{OH}^{-}$ & 1.85 & 1.28 & 0.8 & 0.545 & 1.97 \\
\hline
\end{tabular}

TABLE 2. Feed physical properties

\begin{tabular}{ccccc}
\hline Feed & $\begin{array}{c}\mathrm{T} \\
\left({ }^{\circ} \mathrm{C}\right)\end{array}$ & $\begin{array}{c}\text { Diffusivity } \\
\left(\mathrm{cm}^{2} / \mathrm{min}\right)\end{array}$ & $\begin{array}{c}\text { Density } \\
(\mathrm{g} / \mathrm{ml})\end{array}$ & $\begin{array}{c}\text { Viscosity } \\
(\mathrm{cP})\end{array}$ \\
\hline HC & 25 & $4.935 \times 10^{-4}$ & 1.218 & 2.503 \\
EB & 25 & $6.087 \times 10^{-4}$ & 1.182 & 1.970 \\
SO & 25 & $5.706 \times 10^{-4}$ & 1.218 & 1.979 \\
Tank 3 & 25 & $6.010 \times 10^{-4}$ & 1.245 & 1.830 \\
Tank 37 & 25 & $4.740 \times 10^{-4}$ & 1.232 & 2.590 \\
\hline
\end{tabular}

\section{RESIN PROPERTIES}

Properties for the sRF resin used in this study are the same as those used previously $(13,14)$. For the hypothetical spherical SL644 resin, properties are estimated based on the characteristics and structure of both the granular SL644 resin (12) and the sRF resin. Table 3 summarizes the 
properties for the two resins under consideration. Table 4 lists the Freundlich/Langmuir isotherm parameters for the SRF resin estimated based on the thermodynamic equilibrium data generated by the CERMOD code. The isotherms for the spherical SL644 resin are assumed to be the same as those for the granular SL644. The spherical SL644 isotherm parameters obtained from estimation based on the thermodynamic equilibrium data generated by the TMIXP code are shown in Table 5. In these Tables, resin data and isotherm parameter values for Hanford wastes were extracted from Hamm et al (12) and Aleman et al (13). For Tank 3 and Tank 37, isotherm parameters for the sRF resin were provided by Smith (14), while isotherm parameters for the spherical SL644 resin were calculated by the TMIXP code.

TABLE 3. $\mathrm{Na}^{+}$-form resin physical properties

\begin{tabular}{lcc}
\hline Property & sRF & Spherical SL644 \\
\hline Bed density $\rho_{\mathrm{b}}(\mathrm{g} / \mathrm{ml})$ & 0.32 & 0.2792 \\
Solid density $\rho_{\mathrm{s}}(\mathrm{g} / \mathrm{ml})$ & 1.615 & 1.451 \\
Bed porosity $\varepsilon_{\mathrm{b}}$ & 0.42 & 0.42 \\
Particle porosity $\varepsilon_{\mathrm{p}}$ & 0.6579 & 0.6682 \\
Average particle diameter $(\mu \mathrm{m})$ & 460. & 460. \\
\hline
\end{tabular}

TABLE 4. Freundlich/Langmuir isotherm parameters for the sRF resin

\begin{tabular}{lcccc}
\hline Feed $@ 25^{\circ} \mathrm{C}$ & $\mathrm{a}$ & $\beta$ & $\mathrm{M}_{\mathrm{a}}$ & $\mathrm{M}_{\mathrm{b}}$ \\
\hline $\mathrm{HC}$ & 0.2632 & $2.076 \mathrm{E}-3$ & 0.9850 & 0.8695 \\
EB & 0.2401 & $4.783 \mathrm{E}-4$ & 0.9727 & 0.9042 \\
SO & 0.2458 & $8.174 \mathrm{E}-4$ & 0.9761 & 0.8941 \\
Tank 3 & 0.2373 & $4.805 \mathrm{E}-4$ & 0.9736 & 0.9066 \\
Tank 37 & 0.2345 & $2.737 \mathrm{E}-4$ & 0.9706 & 0.9142 \\
\hline
\end{tabular}

TABLE 5. Freundlich/Langmuir isotherm parameters for the spherical SL644 resin

\begin{tabular}{lcccc}
\hline Feed @ $25^{\circ} \mathrm{C}$ & $\mathrm{a}$ & $\beta$ & $\mathrm{M}_{\mathrm{a}}$ & $\mathrm{M}_{\mathrm{b}}$ \\
\hline HC & 0.1441 & $5.1474 \mathrm{E}-4$ & 1 & 1 \\
EB & 0.1418 & $1.4192 \mathrm{E}-4$ & 1 & 1 \\
SO & 0.1376 & $2.4279 \mathrm{E}-4$ & 1 & 1 \\
Tank 3 & 0.1326 & $2.5520 \mathrm{E}-4$ & 1 & 1 \\
Tank 37 & 0.1444 & $1.3707 \mathrm{E}-4$ & 1 & 1 \\
\hline
\end{tabular}


SRNL-STI-2012-00575

\section{SCIX COLUMN SIMULATIONS}

As envisioned, the SCIX process would treat the stored waste using ion-exchange columns suspended inside a waste tank. The columns will use a selective elutable resin (e.g., sRF or SL644) to remove cesium from the waste. Upon adsorption of cesium, the loaded cesium is eluted, and the cesium-containing eluate will be further processed in a high-level waste facility (e.g., the DWPF glass melter at the SRS). The eluted resin can be reused in another ionexchange cycle.

\section{SCIX Column Design}

The SCIX column design was developed by Oak Ridge National Laboratory and Savannah River National Laboratory. The design overcame earlier issues related to column overheating and long contact time using an annular configuration with an outer diameter of $0.71 \mathrm{~m}$ and a $0.15-\mathrm{m}$ diameter inner cooling tube. The outer tube has a wall thickness of $0.008 \mathrm{~m}$ and the inner tube is $0.15 \mathrm{~m}$ schedule 40 pipe. The cross-sectional area of the annular ion-exchange bed is $0.3575 \mathrm{~m}^{2}$. A column length of $4.57 \mathrm{~m}$ was chosen.

The proposed design consists of two columns used in series during loading, i.e., a lead column (column 1) followed by a lag column (column 2). When the concentration of cesium in the effluent from the lag column reaches a limit value pre-determined based on the required final product compositions (e.g., saltstone), the ion-exchange cycle is stopped. Table 6 lists the required limit cesium concentrations at the lag column exit for each type of waste feeds. The concentration limits for Hanford feeds were obtained from Hamm et al (12). For Tank 3 and Tank 37, the limit concentrations were calculated from the saltstone feed limit of $45 \mathrm{nCi} / \mathrm{g}$. Upon meeting the lag column exit cesium criterion, the lead column is removed from service, the partially loaded lag column is placed in the lead position, a fresh column is placed in the lag 
position and the next cycle is started. With sRF or SL644 resin, cesium will be eluted from the loaded column and the eluted column is placed back into service as the lag column in the next cycle. The resin may be reused until degradation from the exposure to chemicals and radioactivity becomes too great.

TABLE 6. Cesium concentration criterion at the lag column exit

\begin{tabular}{lcc}
\hline Feed & $\begin{array}{c}\text { Lag Column Exit } \mathrm{Cs}^{+} \\
\text {Criterion } \\
\mathrm{Cs}^{+}(\mathrm{M})\end{array}$ & $\begin{array}{c}\text { Lag Column } \mathrm{Cs}^{+} \text {Concentration Ratio } \\
\text { Criterion } \\
\left(\mathrm{C} / \mathrm{C}_{\mathrm{o}}\right)\end{array}$ \\
\hline Hot commissioning & $3.70 \times 10^{-8}$ & $1.35 \times 10^{-3}$ \\
Envelope B & $3.40 \times 10^{-8}$ & $1.20 \times 10^{-4}$ \\
Subsequent operations & $3.40 \times 10^{-8}$ & $6.80 \times 10^{-4}$ \\
Tank 3 & $4.70 \times 10^{-9}$ & $7.40 \times 10^{-5}$ \\
Tank 37 & $4.65 \times 10^{-9}$ & $4.30 \times 10^{-5}$ \\
\hline
\end{tabular}

\section{Column Performance Case Studies}

The objective of this work is, through computer modeling, to predict the performance (i.e., number of processing cycles) of both sRF and spherical SL644 resins for the removal of cesium from Hanford and SRS wastes. The study investigated the column performance in the following cases:

1. Nominal flow rate $(1.39 \mathrm{BV} / \mathrm{h})$

2. High flow rate $(2.78 \mathrm{BV} / \mathrm{h})$

3. Low flow rate $(0.695 \mathrm{BV} / \mathrm{h})$

For the SRS wastes stored in tanks 3 and 37, simulations were carried out until the tanks were empty. For Hanford wastes, since specific tanks are not known, the cases were simulated sufficiently long (e.g., $1800 \mathrm{BV}$ ) to obtain a meaningful number of cycles.

\section{MODELING RESULTS}

\section{Column Performance}

All column performance study cases were carried out for the Hanford and SRS waste feeds to 
predict the performance of both SRF and spherical SL644 resins for cesium removal. Note that during the first cycle, both columns contain fresh resin. After the first cycle in all subsequent cycles, the partially loaded lag column is placed into the lead position and a clean (eluted) column is placed into the lag position at the start of the cycle. Since, after the first cycle, a partially loaded column is in the lead position, less waste volume is processed per cycle before the cesium concentration operating limit is reached.

For illustration, the results for the Hot Commissioning and Tank 37 feeds in the nominal flow rate case are shown in Figures 2 through 5 for both sRF and spherical SL644 resins. In these Figures, the cesium concentrations relative to the feed concentrations $\left(\mathrm{C} / \mathrm{C}_{\mathrm{o}}\right)$ are displayed at the exit of the lead column (solid line) and the lag column (dashed line), respectively. As described above, the ion-exchange cycle is stopped, when the effluent concentration of cesium in the lag column reaches the specified limit value. The lead column is then removed from service, and the lag column becomes the lead column. A fresh column is placed in the lag position and a new cycle begins. Hence, in Figures 2 through 5, a complete "spike" represents a full cycle. 


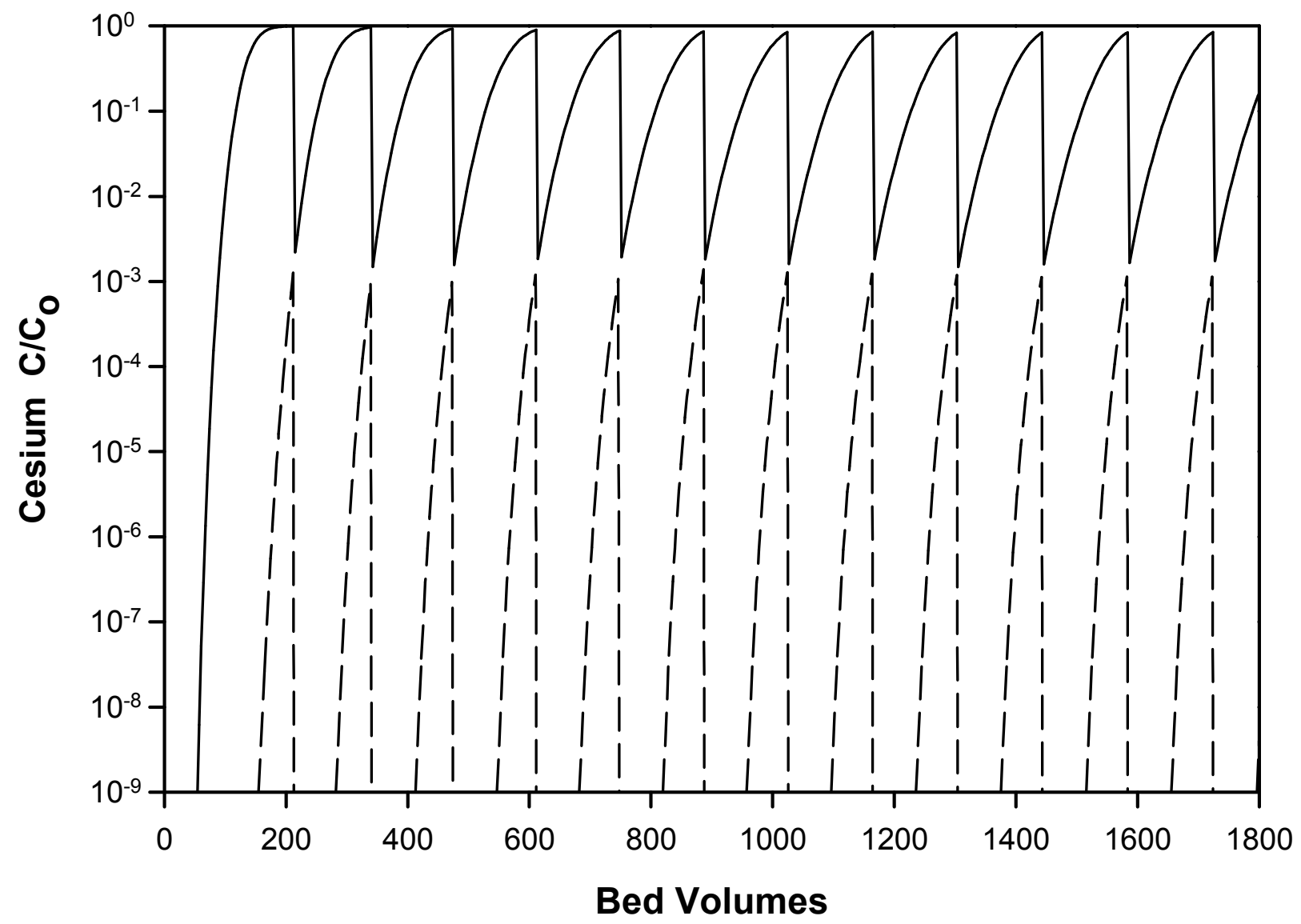

FIG. 2. Cesium breakthrough prediction for Hot Commissioning Operations feed at nominal condition with $460 \mu \mathrm{m}$ diameter RF spheres (— Lead column; --- Lag column) 




FIG. 3. Cesium breakthrough prediction for Hot Commissioning Operations feed at nominal condition with $460 \mu \mathrm{m}$ diameter SL644 spheres (- Lead column; --- Lag column) 


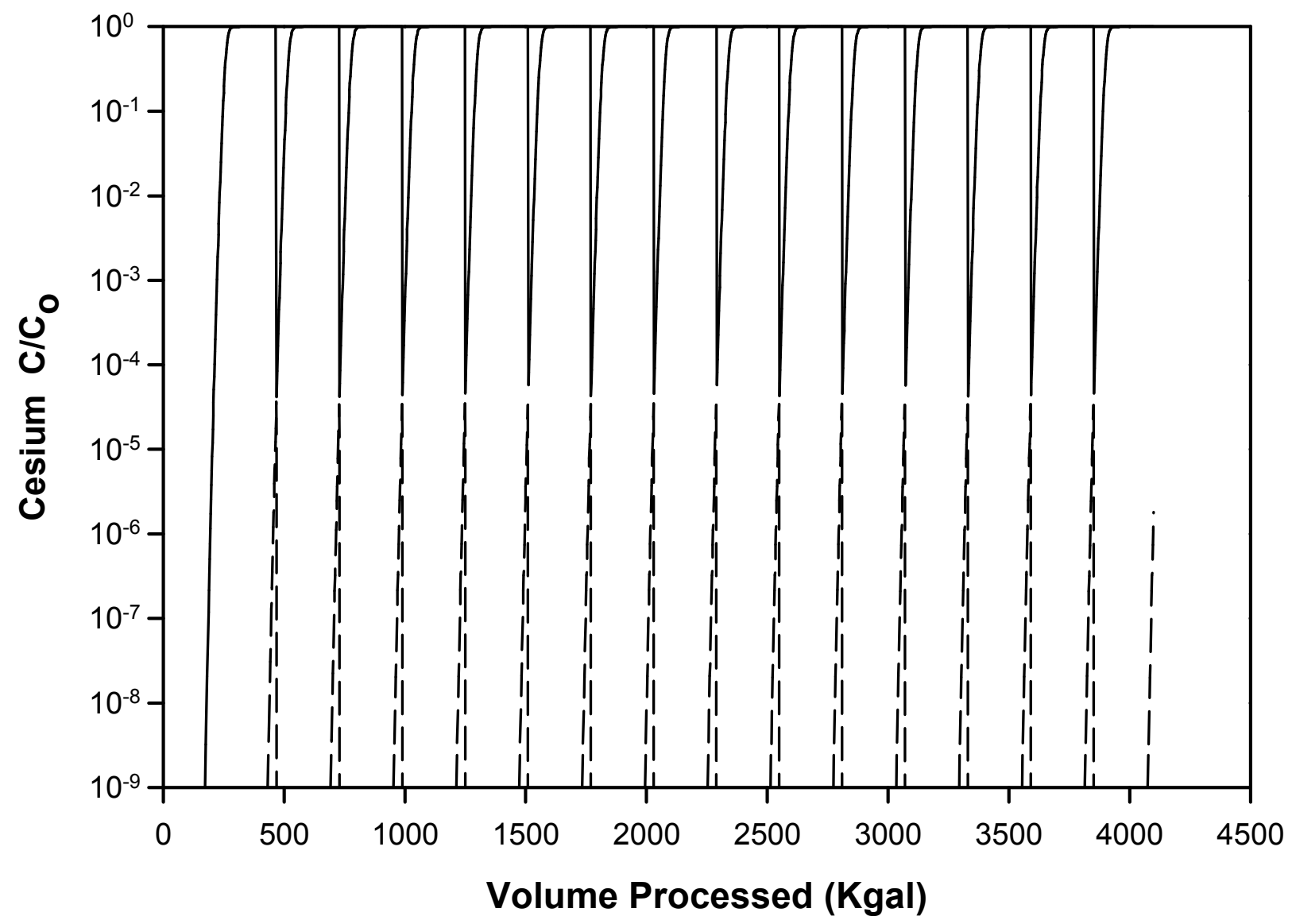

FIG. 4. Cesium breakthrough prediction for Tank 37 feed at nominal condition with $460 \mu \mathrm{m}$ diameter RF spheres (— Lead column; --- Lag column) 


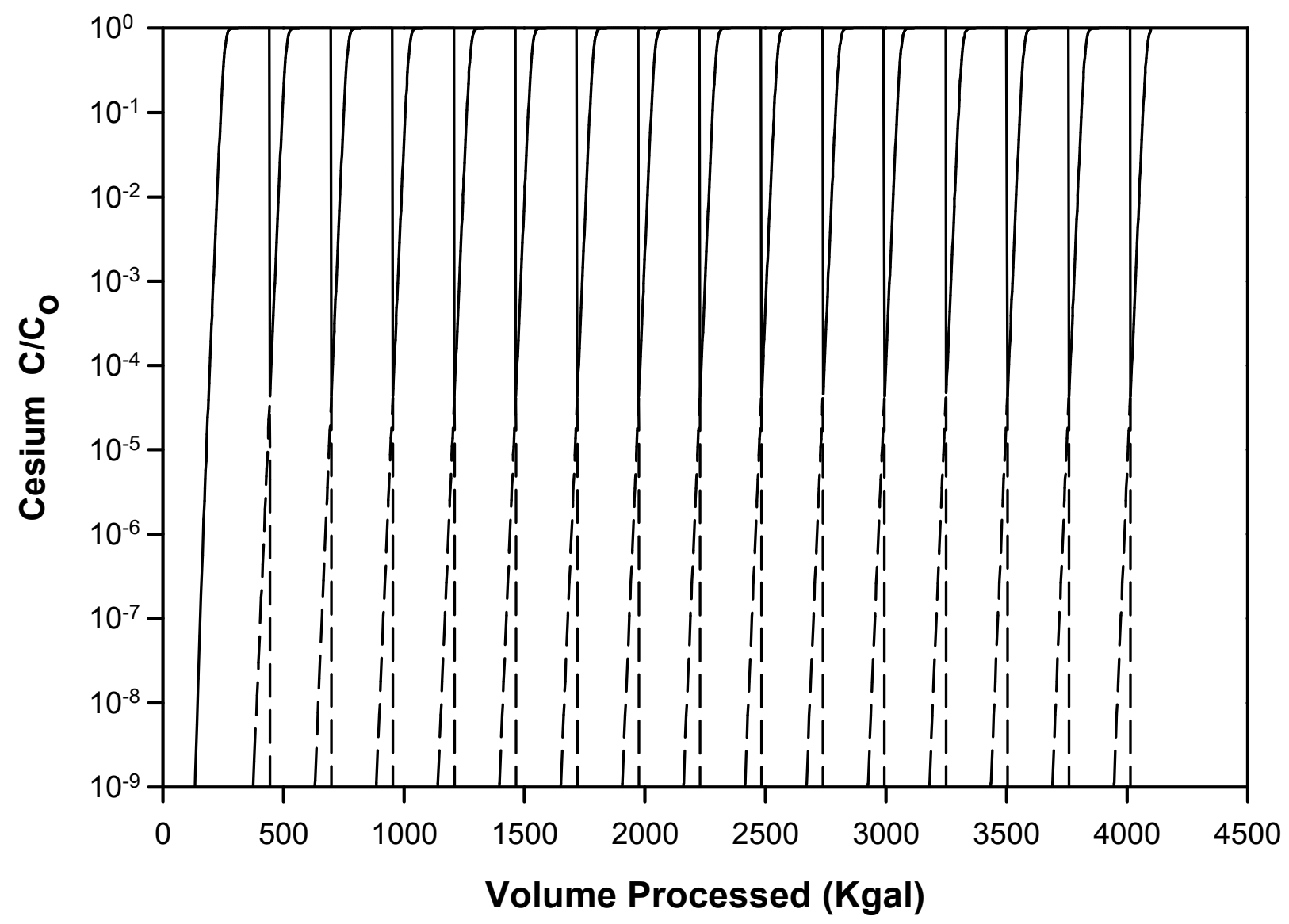

FIG. 5. Cesium breakthrough prediction for Tank 37 feed at nominal condition with $460 \mu \mathrm{m}$ diameter SL644 spheres (— Lead column; --- Lag column) 
Table 7 provides a summary of the number of processing cycles predicted for both resins at the nominal, high and low flow rate conditions. In Table 7, the resin performance is predicted based on $1800 \mathrm{BVs}$ for the Hanford wastes and on the tank capacity for the SRS wastes. The ratios of number of sRF cycles and spherical SL644 cycles are computed for comparison of the resin performances. Spherical SL644 performs better when the ratio is larger than 1, while the lessthan-1 ratio indicates a better performance for sRF. As discussed above, the relative affinities for adsorption were computed to be $\mathrm{Cs}^{+}>\mathrm{Rb}^{+}>\mathrm{K}^{+}>\mathrm{Na}^{+}$for the sRF resin and $\mathrm{Cs}^{+}>>\mathrm{K}^{+}>\mathrm{Na}^{+}$ for the SL644 resin. That means, $\mathrm{K}^{+}$would compete more against $\mathrm{Cs}^{+}$for adsorption onto sRF than onto SL644. Consequently, the presence of high $\mathrm{K}^{+}$concentration in a waste would eventually decrease cesium sorption on the sRF resin, resulting in more processing cycles. Table 7 confirms this phenomenon at all flow rates. 
TABLE 7. Performances for the sRF and spherical SL644 resins

\begin{tabular}{lccc}
\hline & \multicolumn{2}{c}{ Number of cycles } & Ratio of number of cycles \\
& sRF & spherical SL644 & sRF/spherical SL644 \\
\hline Nominal HC & 12 & 6 & 2.00 \\
Nominal EB & 5 & 4 & 1.25 \\
Nominal SO & 4 & 3 & 1.33 \\
Nominal Tank 3 & 9 & 11 & 0.82 \\
Nominal Tank 37 & 14 & 15 & 0.93 \\
\hline High-flow HC & 13 & 7 & 1.86 \\
High-flow EB & 5 & 4 & 1.25 \\
High-flow SO & 5 & 3 & 1.67 \\
High-flow Tank 3 & 9 & 11 & 0.82 \\
High-flow Tank 37 & 15 & 15 & 1.00 \\
\hline Low-flow HC & 12 & 6 & 2.00 \\
Low-flow EB & 5 & 4 & 1.25 \\
Low-flow SO & 4 & 3 & 0.90 \\
Low-flow Tank 3 & 9 & 10 & 0.93 \\
Low-flow Tank 37 & 14 & 15 &
\end{tabular}

\section{Bleed Tests}

Experimental column work with sRF resin has shown that elution leaves a small amount of cesium in the resin bed. For example, multiple lab-scale column runs by Pacific Northwest National Laboratory (PNNL) measured such bleed for SL644 and various RF resin types (22). High potassium wastes typically cause resins to show relatively the highest cesium bleeds in follow-on cycles. Cesium can bleed into otherwise decontaminated product in the next loading 
cycle. PNNL also provided cesium bleed measurements when sRF beds were used in testing with actual Hanford Tank 241-AN-102 waste solution (23).

Table 8 shows the specified input parameters to the VERSE model to simulate bleed. First, a uniform cesium loading for the resin bed was applied. The indicated feed, either Envelope B or Tank 3 waste solution, then flowed through the bed with zero feed cesium concentrations. These situations could only cause cesium to bleed from the resin to the liquid stream. Figures 6 and 7 show the simulation results. Liquid-phase cesium quickly rises to the equilibrium value near the entry point in the bed. During hundreds of bed volumes of feed, the liquid cesium concentration at the exit of the bed remains practically constant at the equilibrium value. The modeled bleed is in effect an elution of cesium from the resin. The alkaline liquid feed is however not efficient at displacing cesium from the resin because the liquid cesium concentration at equilibrium with the resin cesium is relatively low. This was found to be true for both Envelope B and Tank 3. If mass transfer resistance were controlling, the cesium concentration curves would not be sharp as shown - exiting liquid would not be at equilibrium with resin cesium content. The model thus provides clear indications that cesium bleed is a cesium isotherm-controlled versus mass transfer controlled mechanism. This is a preliminary basis for predicting bleed effects and the need to elute resin down below a certain cesium content.

TABLE 8. Bleed test specifications

\begin{tabular}{lcc}
\hline & Envelope B with sRF & Tank 3 with sRF \\
\hline Number of columns & 1. & 1. \\
Load (BV/hr) & 0.72 & 1.4 \\
Resin initial Cs & & \\
$\left(\mu \mathrm{g} \mathrm{Cs} / \mathrm{g}-\mathrm{resin}\left(\mathrm{H}^{+}\right.\right.$form $\left.)\right)$ & 0.4 & 2.5 \\
Initial liquid Cs $^{+}(\mathrm{mol} / \mathrm{L})$ & 0. & 0. \\
$\mathrm{Cs}^{+}$in feed $(\mathrm{mol} / \mathrm{L})$ & 0. & 0. \\
\hline
\end{tabular}




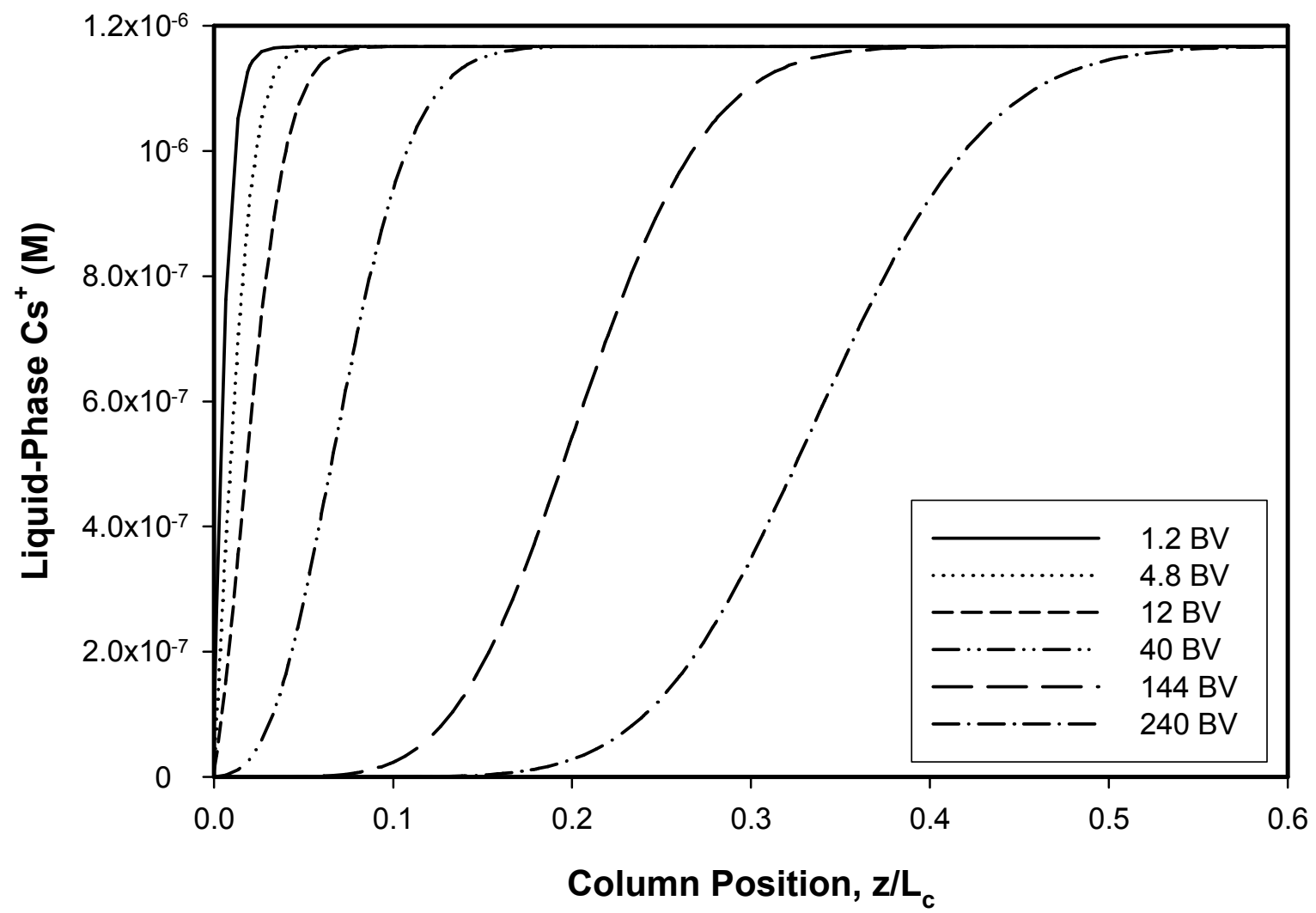

FIG. 6. Column Liquid-Phase $\mathrm{Cs}^{+}$Concentration Profile (Envelope B feed at a flow rate of 0.72 $\mathrm{BV} / \mathrm{h}$ and a temperature of $25^{\circ} \mathrm{C}$ with $460 \mu \mathrm{m}$ diameter $\mathrm{RF}$ spheres) 


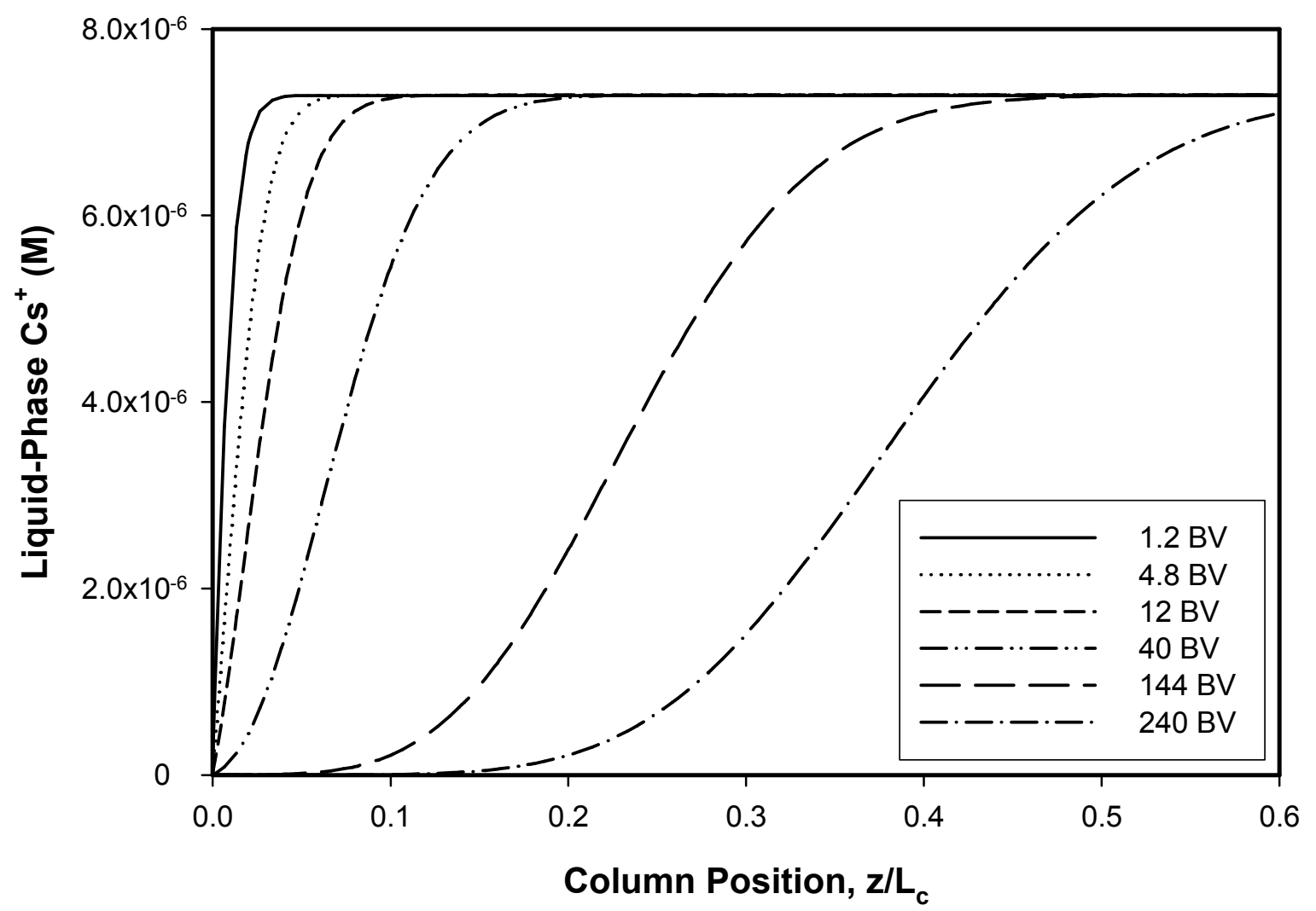

FIG. 7. Column Liquid-Phase $\mathrm{Cs}^{+}$Concentration Profile (Tank 3 feed at a flow rate of $1.4 \mathrm{BV} / \mathrm{hr}$ and a temperature of $25^{\circ} \mathrm{C}$ with $460 \mu \mathrm{m}$ diameter RF spheres) 
SRNL-STI-2012-00575

\section{CONCLUSIONS}

Using the VERSE-LC code the spherical sRF and hypothetical spherical SL644 ion-exchange resins were evaluated for the removal of cesium from SRS and Hanford radioactive waste solutions. The study cases show that spherical SL644 reduces column cycling by $50 \%$ for highpotassium solutions, and sRF performs equally well for the lowest potassium wastes. Less cycling significantly reduces life-cycle operational costs since less nitric acid usage during resin elution and less sodium addition during resin regeneration are required.

A model assessment of the mechanism behind "cesium bleed" was also conducted. When a resin bed is eluted, a relatively small amount of cesium remains within resin particles. Cesium can bleed into otherwise decontaminated product in the next loading cycle. The model clearly indicates that the bleed mechanism is fully isotherm-controlled vs. mass transfer controlled. Knowledge of residual post-elution cesium level and resin isotherm can be utilized to predict rate of cesium bleed in a mostly non-loaded column.

This work has demonstrated the versatility of the ion-exchange modeling to study the effect of resin characteristics on column performance. This evaluation justifies further development of a spherical form of the SL644 resin. 


\section{NOMENCLATURE}

a Freundlich/Langmuir Hybrid isotherm model coefficient, mol/1 $\mathrm{BV}_{\mathrm{BV}}$

C Bulk phase solute concentration, mol/1

$\overline{\mathrm{C}}_{\mathrm{p}} \quad$ VERSE-LC solid-phase solute concentration, $\mathrm{mol} / \mathrm{l}_{\mathrm{BV}}$

$\overline{\mathrm{C}}_{\mathrm{T}} \quad$ Total ion-exchange capacity of resin, $\mathrm{mmol} / \mathrm{g}$

$\mathrm{C}_{\mathrm{p}} \quad$ Pore phase solute concentration, mol/1

$\mathrm{C}_{\mathrm{o}} \quad$ Column inlet solute concentration, $\mathrm{mol} / \mathrm{l}$

$\mathrm{D}_{\mathrm{p}} \quad$ Pore diffusivity, $\mathrm{cm}^{2} / \mathrm{min}$

$\mathrm{D}_{\infty} \quad$ Bulk diffusivity, $\mathrm{cm}^{2} / \mathrm{min}$

$\mathrm{E}_{\mathrm{b}} \quad$ Axial dispersion coefficient, $\mathrm{cm}^{2} / \mathrm{min}$

Mass transfer (Wilson and Geankoplis correlation)

$\mathrm{k}_{\mathrm{f}} \quad$ Film mass transfer coefficient, $\mathrm{cm} / \mathrm{min}$

$\mathrm{L}_{\mathrm{c}} \quad$ Column length, $\mathrm{cm}$

$\mathrm{M}_{\mathrm{a}} \quad$ Freundlich/Langmuir Hybrid isotherm model exponent

$\mathrm{M}_{\mathrm{b}} \quad$ Freundlich/Langmuir Hybrid isotherm model exponent

Q Solid-phase solute concentration, $\mathrm{mol} / \mathrm{l}_{\mathrm{SV}}$

Radial position from center of adsorbent particle, $\mathrm{cm}$

Re Reynolds number

$\mathrm{R}_{\mathrm{p}} \quad$ Resin particle radius, $\mathrm{cm}$

Sc Schmidt number

$\mathrm{t}$

Time, $\min$

$\mathrm{u}_{\mathrm{o}} \quad$ Linear interstitial velocity, $\mathrm{cm} / \mathrm{min}$ 
$\mathrm{Z}$

$\beta$

$\varepsilon_{\mathrm{b}}$

$\varepsilon_{p}$

$\mu$

$\rho$

$\rho_{\mathrm{b}}$

$\rho_{\mathrm{s}}$

$\tau$
Position in axial direction, $\mathrm{cm}$

Freundlich/Langmuir Hybrid isotherm model coefficient

Bed porosity

Particle porosity

Solution viscosity, $\mathrm{g} /(\mathrm{cm} . \mathrm{min})$

Solution density, $\mathrm{g} / \mathrm{ml}$

Bed density, $\mathrm{g} / \mathrm{ml}$

Solid density, $\mathrm{g} / \mathrm{ml}$

Particle tortuosity factor 
SRNL-STI-2012-00575

\section{REFERENCES}

1. Ayers, J.A. (1951) Treatment of radioactive waste by ion exchange. Ind. \& Eng. Chem., 43 (7): 1526-1531.

2. International Atomic Energy Agency (IAEA). (2002) Application of ion exchange processes for the treatment of radioactive waste and management of spent ion exchangers. Tech. Report Series No. 408, Vienna.

3. Anthony, R.G.; Philip, C.V.; Dosh, R.G. (1993) Selective adsorption and ion exchange of metal cations and anions with silico-titinates and layered titinates. Waste Management, 13 (5-7): 503-512.

4. Samanta, S.K.; Ramaswamy, M.; Misra, B.M. (1992) Studies on cesium uptake by phenolic resin. Sep. Sci. Technol., 27 (2): 255-267.

5. Samanta, S.K.; Theyyunni, T.K.; Misra, B.M. (1994) Column behavior of resorcinolformaldehyde polycondensate resin for radiocesium removal from simulated radwaste solution. J. Nuc. Sci. Technol., 32 (5): 425-429.

6. Ebra, M.A.; Wallace, R.M. Phenolic Cation Exchange Resin Material for Recovery of Cesium and Strontium. U.S. Patent 4,423,159, 1983.

7. Adamson, D.J.; Fowley, M.D.; Steimke, J.L.; Steeper, T.J.; Williams, M.; Duffey, C.E.; Fondeur, F.F. (2006) Pilot-Scale Hydraulic Testing of Resorcinol Formaldehyde Ion Exchange Resin; WSRC-TR-2005-00570, Westinghouse Savannah River Co.: Aiken, SC.

8. Arm, S.T.; Blanchard Jr., D.L.; Brooks, K.P.; Buchmiller, W.C.; B. J. Cook, B.J.; Cuta, J.M.; Fiskum, S.K.; Hontz, Z.; Isackson, C.; Schepmoes, A.A.; and Wallace, D.E. (2006) Laboratory Scale Hydraulic Testing of Spherical Resorcinol Formaldehyde Ion Exchange Resins; WTP-RPT-142, Battelle Pacific Northwest National Laboratory: Richland, WA. 
SRNL-STI-2012-00575

9. Duignan, M.R., Nash, C.A.; Punch, T.M. (2008) High Aspect Ratio Ion Exchange Resin Bed - Hydraulic Results for Spherical Resin Beads. Sep. Sci. Technol., 43 (9-10): 2943-2979.

10. Bray, L.A.; Amonette, J.E.; Brown, G.N.; Kafka, T.M.; Yates, S.F. (1995) Efficient Separations and Processing Crosscutting Program: Develop and Test Sorbents; a FY 1995 Annual Progress Report, PNL-10750 (UC-2030), Battelle Pacific Northwest National Laboratory: Richland, WA.

11. Brown, G.N.; Adami, S.R.; Bray, L.A.; Bryan, S.A.; Carlson, C.D.; Carson, K.J.; Deschane, J.R.; Elovich, R.J.; Forbes, S.J.; Franz, J.A.; Linehan, J.C.; Shaw, W.J.; Tanaka, P.K.; Telander, M.R. (1995) Chemical and Radiation Stability of SuperLig ${ }^{\circledR}$ 644, ResorcinolFormaldehyde, and CS-100 Cesium Ion Exchange Materials; PNL-10772 (UC-2030), Battelle Pacific Northwest National Laboratory: Richland, WA.

12. Hamm, L.L.; Aleman, S.E.; Hardy, B.J.; King, W.D.; and Duffey, C.E. (2004) Ion Exchange Modeling for Removal of Cesium from Hanford Waste Using SuperLig ${ }^{\circledR} 644$ Resin; WSRCTR-2003-00555 (SRT-RPP-2003-00242), Rev. 0, Westinghouse Savannah River Co.: Aiken, $\mathrm{SC}$.

13. Aleman, S.E.; Hamm, L.L.; Smith III, F.G. (2007) Ion Exchange Modeling of Cesium Removal from Hanford Waste Using Spherical Resorcinol-Formaldehyde Resin; WSRC-STI2007-00030, Rev. 0, Washington Savannah River Co.: Aiken, SC.

14. Smith III, F.G. (2007) Modeling of Ion Exchange for Cesium Removal from Dissolved Saltcake in SRS Tanks 1-3, 37 and 41; WSRC-STI-2007-00315, Rev. 0, Washington Savannah River Co.: Aiken, SC.

15. Smith III, F.G.; Hamm, L.L.; Aleman, S.E.; Johnson, M.E. (2009) Modeling ion-exchange for cesium removal from alkaline radioactive waste solution. Sep. Sci. Technol., 44 (13): 
SRNL-STI-2012-00575

$2983-3012$.

16. Whitley, R.D.; Wang, N.-H.L. (1998) User's Manual VERSE (VErsatile Reaction SEparation) Simulation for Liquid Phase Adsorption and Chromatography Processes; School of Chemical Engineering, Purdue University.

17. Berninger, J.; Whitley, R.D.; Zhang, X.; Wang, N.-H.L. (1991) A versatile model for simulation of reaction and nonequilibrium dynamics in multicomponent fixed-bed adsorption processes. Comp. Chem. Eng., 15 (11): 749-768.

18. Hamm, L.L.; Smith III, F.G.; Shadday, M.A. (2000) QA Verification Package for VERSELC Version 7.80; WSRC-TR-99-00238, Westinghouse Savannah River Co.: Aiken, SC.

19. Aleman, S.E.; Hamm, L.L. (2007) Detailed Thermodynamic Equilibrium Model for the Prediction of Ion Exchange Behavior on Monovalent Cation Exchange Resins; WSRC-STI2007-00054, Rev. 0, Washington Savannah River Co.: Aiken, SC.

20. Chung, S.F.; Wen, C.Y. (1968) Longitudinal dispersion of liquid flowing through fixed and fluidized beds. AIChE J., 14 (6): 857-866.

21. Wilson, E.J.; Geankoplis, C.J. (1966) Liquid mass transfer at very low Reynolds numbers in packed beds. Ind. Eng. Chem. Fund., 5 (1): 9-14.

22. Fiskum, S.K.; Augspurger, B.S.; Brooks, K.P.; Buchmiller, W.C.; Russell, R.L.; Schweiger, M.J.; Snow, L.A.; Steele, M.J.; Thomas, K.K.; Wallace, D.E.; Wong, N.H.; Yeager, J.D.; Blanchard Jr., D.L. (2004) Comparison Testing of Multiple Resorcinol Formaldehyde Resins for the River Protection Project - Waste Treatment Plant; WTP-RPT-103 (PNWD-3387), Rev. 0, Battelle Pacific Northwest National Laboratory: Richland, WA.

23. Fiskum, S.K.; Steele, M.J.; Blanchard Jr., D.L. (2006) Small Column Ion Exchange Testing of Spherical Resorcinol-Formaldehyde Resin for Cs-137 Removal from Pre-Treated Hanford 
Tank 241-AN-102 Waste (Envelope C); WTP-RPT-135, Battelle Pacific Northwest National Laboratory: Richland, WA. 